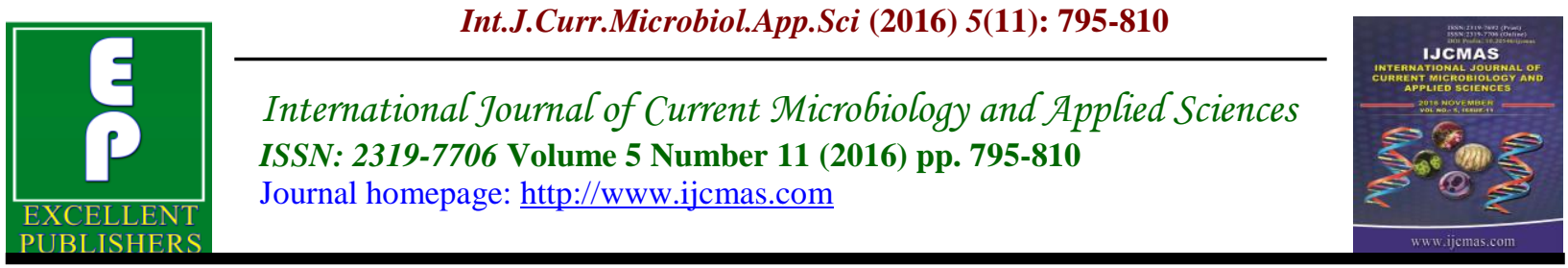

Original Research Article

http://dx.doi.org/10.20546/ijcmas.2016.511.091

\title{
Diabetes Mellitus and its Control by Ocimum sanctum Extract in Mice Diabetic Model
}

\author{
Utsav $^{1}$, Baidyanath Kumar $^{2 *}$ and Atul Kumar ${ }^{3}$ \\ ${ }^{1}$ Research scholar, Department of Biotechnology, Maharishi Markendeshwar University, \\ Mullana, Ambala (Haryana), India \\ ${ }^{2}$ Visiting Professor, Department of Biotechnology, Patna Science College, Patna (Bihar), India \\ ${ }^{3}$ Research Scholar, Department of Biotechnology, College of Commerce (MU), Patna, India \\ *Corresponding author
}

Keywords

Diabetes mellitus,

Ocimum sanctum,

Streptozotocin,

Antidiabetic,

Mice.

Article Info

Accepted:

26 October 2016

Available Online:

10 November 2016

\section{A B S T R A C T}

Diabetes mellitus is the most prevalent metabolic syndrome world- wide and is characterized by hyperglycemia resulting in various short- term metabolic changes in lipid and protein metabolism and long- term irreversible vascular changes which include diabetic- specific complications viz., retinopathy, nephropathy and neuropathy. Diabetes mellitus (DM) is a metabolic disorder of multiple etiologies characterized by absolute or relative deficiency of insulin secretion with or without varying degree of insulin resistance. Sedentary life style and obesity are two major epidemiological determinants of diabetes mellitus. In the present investigation hypoglycemic efficacy of Ocimum sanctum methanol extract was tested on STZ induced mice diabetic models. The results clearly indicated that the diabetic control (DC) mice presented a significant lowering of body weight $(p<0.001)$ when compared with the normal control (NC) mice. The DC mice showed a significantly $(p<0.001)$ higher level of glucose $(+279 \%)$, when compared with their normal control counterparts. Diabetic mice of both of the groups (DT150 and DT250) showed a reduction in glucose levels, when compared to the DC ones. The results clearly indicated that the $O$. sanctum whole plant methanol extract is antidiabetic in nature due to the presence of different types of active phytochemicals.

\section{Introduction}

Diabetes mellitus is a syndrome with disordered metabolism and inappropriate hyperglycemia due to either a deficiency of insulin secretion or to a combination of insulin resistance and inadequate insulin secretion to compensate. There are two classes of diabetes mellitus, Type- 1 and Type- 2. Type- 1 diabetes is due to pancreatic islet $B$ cell destruction predominantly by an autoimmune process, and these patients are prune to ketoacidosis. Type- 2 diabetes is the more prevalent form and results from insulin resistance with a defect in compensatory insulin secretion.

In over $90 \%$ of cases Type- 1 diabetes is immune- mediated and in less than $10 \%$ cases it is idiopathic. The rate of pancreatic $\mathrm{B}$ cell destruction is quite variable. Type- 1 diabetes is usually associated with ketosis in 
its untreated state. It occurs most commonly in juveniles, with highest incidence among the 10 to 14- year- old group, but occasionally occurs in adults, especially the non obese and those who are elderly when hyperglycemia first appears. It is a catabolic disorder in which circulating insulin is virtually absent, plasma glucagon is elevated, and the pancreatic B cell fail to respond to all insulinogenic stimuli. Exogenous insulin is therefore required to reverse the catabolic state, prevent ketosis, reduce the hyperglucagonemia, and reduce blood glucose.

Certain human leukocyte antigens (HLA) are strongly associated with the development of Type- 1diabetes (Umesh Masharani and John (2003). About 95\% of Type- 1 patients possess either HLA- DR3 or HLA- DR4, compared with $45 \%-50 \%$ of Caucasian controls. HLA- DQ genes are even more specific markers of Type- 1 susceptibility, since a particular variety (HLA- DQB1*0302) is found in the DR4 patients with Type- 1, while a "protective" gene (HLA- DQBI*0602) is often present in the DR4 controls. In addition, circulating islet cell antibodies have been detected in as many as $85 \%$ of patients, and the majority of these patients also have detectable antiinsulin antibodies prior to receiving insulin therapy (Umesh Masharani and John Karam, 2003). Most islet cell antibodies are directed against glutamic acid decarboxylase, an enzyme localized within pancreatic B cells.

Immune- mediated Type- 1 diabetes is felt to result from an infectious or toxic insult to persons whose immune system is genetically predisposed to develop a vigorous autoimmune response either against altered pancreatic $B$ cell antigens or against molecules of the $\mathrm{B}$ cell resembling the viral protein (molecular mimicry). Extrinsic factors that affect $B$ cell function include damage caused by viruses such as mumps or coxsackie B4 virus, by toxic chemical agents, or by destructive cytotoxins and antibodies released from sensitized immunocytes. Specific HLA immune response genes are believed to predispose patients to a destructive autoimmune response against their own islet cells (auto aggression) which is mediated primarily by cytotoxic $\mathrm{T}$ cells. In such patients immunosuppressive agent (e.g. cyclosporine) is given to ameliorate hyperglycemia.

Type- 2 diabetes represents a heterogeneous group comprising milder forms of diabetes that occur predominantly in adults but occasionally in juveniles. More than $90 \%$ of all diabetics are included under this classification. Circulating endogenous insulin is sufficient to prevent ketoacidosis but is inadequate to prevent hyperglycemia in the face of increased needs owing to tissue insensitivity. In most cases of this type of diabetes, the cause is unknown.

Tissue insensitivity to insulin has been noted in most Type- 2 patients irrespective of weight and has been attributed to several interrelated factors. These include a putative genetic factor, which is aggravated in time by additional enhancers of insulin resistance such as aging, a sedentary lifestyle, and abdominal- visceral obesity. In addition, there is an accompanying deficiency in the response of pancreatic B cells to glucose. Both the tissue resistance to insulin and the impaired B cell response to glucose appear to be further aggravated by increased hyperglycemia, and both defects are ameliorated by treatment that reduces the hyperglycemia towards normal. Most epidemiologic data indicate strong genetic influences in Type- 2 diabetes. The genetic factors responsible for Type- 2 diabetes have not yet been identified, though linkage to a 
gene on chromosome 2 encoding a cysteine protease, calpain- 10 has been reported in a Mexican- American population.

Diabetes mellitus has been classified into some other specific types.

Maturity- onset diabetes of the young (MODY): This subgroup is a relatively rare monogenic disorder characterized by noninsulin- dependent diabetes with autosomal dominant inheritance and an age at onset of 25 years or younger. Patients are nonobese, and their hyperglycemia is due to impaired glucose- induced secretion of insulin.

Diabetes due to mutant insulin: This is a very rare subtype of nonobese Type- 2 diabetes. Since affected individuals were heterozygous and possessed one normal insulin gene, diabetes was mild, and showed autosomal dominant genetic transmission.

\section{Diabetes due to mutant insulin receptors:} In more than 40 people with diabetes, defects in one of their insulin receptor gene have been observed.

\section{Diabetes mellitus associated with a} mutation of mitochondrial DNA: Diabetes due to a mutation of mitochondrial DNA that impairs the transfer of leucine or lysine into mitochondrial proteins has been described. Most patients have a mild form of diabetes that responds to oral hypoglycemic agents. Two- thirds of patients with this subtype of diabetes have a hearing loss, and a smaller proportion had a syndrome of myopathy, encephalopathy, lactic acidosis, and stroke- like episodes (MELAS).

Obese Type- 2 patients: The most common form of diabetes is secondary to extra pancreatic factors that produce insensitivity to endogenous insulin. When an associated defect of insulin production prevents adequate compensation for this insulin resistance, nonketotic mild diabetes occurs. The primary problem is a "target organ" disorder resulting in ineffective insulin action that can secondarily influence pancreatic B cell function.

\section{Chronic Complications of Diabetes}

Diabetes mellitus is associated with late clinical manifestations that include a number of pathologic changes that involve small and large blood vessels, cranial and peripheral nerves, and the lenses of eye. These lesions lead to hypertension, renal failure (nephropathy), blindness (retinopathy), autonomic and peripheral neuropathy, amputations of the lower extremities, myocardial infarction, and cerebrovascular accidents.

Type- 2 diabetes is the commonest form of diabetes constituting $90 \%$ of the diabetic population. The global prevalence of diabetes is estimated to increase to $5.4 \%$ by the year2025 (King Aubert and Herman, 1998). The World Health Organization has predicted that the major burden will occur in the developing countries. The countries with the largest number of diabetic people are, and will be India, China and United States in 2025 (King and Herman, 1998). Epidemiological studies among migrant Asian Indians showed higher prevalence of Type- 2 diabetes compared with the host populations and other migrant ethnic groups (Zimmet, 1999). Studies conducted in India have highlighted that not only is the prevalence of Type- 2 diabetes high, but also that it is increasing rapidly in the urban population (Mohan et al., 2001; Raman Kutty et al., 2000; Misra, 2001; Verma and Madhu, 2000; and Iyer, 2000). The burden of Type- 2 diabetes and its complications related to Indian scenario has been illustrated by Ramachandran et al., (2002). 
The genetics of Type- 2 diabetes has been reviewed by Torben Hansen (2002). BeckNielson and Groop (1994) have suggested that the diabetic phenotype is the result of interaction of both genetic component and an important non- genetic component.

The coexistence of obesity, glucose intolerance, dyslipidemia, and hypertension, is termed as insulin resistance syndrome (IRS). Gerald Reaven (1988) initially proposed that resistance to insulin- mediated glucose disposal is the pathophysiological interface for several complex metabolic alterations and disease. Insulin resistance syndrome in Asian Indians has been reviewed by AnoopMisra and Naval k. Bikram (2002). Regarding chromosomal abnormalities deletion syndrome due to chromosome $22 \mathrm{q} 11.2$ has been investigated by Elder et al., (2001).

Transient neonatal diabetes mellitus (TNDM) is a rare condition which represents with intrauterine growth retardation, dehydration, and failure to thrive. The condition spontaneously resolves before 1 year of age but predisposes patients to Type- 2 diabetes later in life. Rebecca J Gardner et al., (1999) have previously shown that, in some cases, TNDM is associated with paternal uniparentaldisomy (UPD) of chromosome 6and suggested that an imprinted gene responsible for TNDM lies within a region of chromosome $6 \mathrm{q}$. By analyzing three families, two with duplications (family $\mathrm{A}$ and patient $\mathrm{C}$ ) and one with several affected subjects with normal karyotypes (family B), Elder et al., (2001) have further defined the TNDM critical region. In patient $A$, polymorphic microsatellite repeat analysis identified a duplicated region of chromosome 6 , flanked by markers D6S472 and D6S311. This region was identified on the Sanger Centre's chromosome 6 radiation hybrid map (http://www.sanger.ac.uk/HGP/Chr6) and spanned approximately 60 cR3000. Using markers within the region, 418 unique P1derived artificial chromosomes (PACs) have been isolated and used to localize the distal breakpoints of the two duplications. Linkage analysis of the familial case with abnormal karyotype identified a recombination within the critical region. This recombination has been identified on the radiation hybrid map and defines the proximal end of the region of interest. They therefore propose that an imprinted gene for TNDM lies within an 18.72 cR3000 $(\sim 5.4 \mathrm{Mb})$ interval on chromosome $6 \mathrm{q} 24.1$ q24.3between markers D6S1699 and D6S1010.

Vladimir Bakalov et al., (2009) have investigated that Turner syndrome (TS) is caused by the absence or fragmentation of the second sex chromosome, which is associated with increased risk of diabetes mellitus (DM), but the specific phenotype and genetic etiology of this trait are unknown.

Cytogenetic factors related with diabetes have been largely reviewed by (Bekalov et al., 2004; Salgin et al., 2006; Song et al., 2008; Neve et al., 2005; Senee et al., 2006; Zhao et al., 2005; Mokhtari et al., 2008 etc). Suheir Assady (2009) has suggested the stem cell based therapy of diabetes mellitus.

The current therapy of this disorder includes exogenous insulin administration (particularly in case of Type-1 diabetes mellitus), and oral hypoglycemic agents (for Type-2DM) which includes Metformin, Pioglitazone, Sulphonylurea etc. which may have adverse effects in diabetic subjects. Multiple risk factors for diabetes have been identified (WHO, 2006). The greatest risk is impaired glucose tolerance, a precursor of diabetes. Thus, a number of type 2 diabetes prevention trials have included subjects with 
impaired glucose tolerance. These trials compared intensive lifestyle modifications (e.g., diet, exercise and weight loss), OHAs and placebo controls (Tuomilehto et al., 2001; Knowler et al., 2002). Ayurvedic treatment known as Apatarpana (balanced diet with restricted calories) and Santarpana (highly nutritious, high-calorie diet intended to increase weight) are recommended for patients with type 2 and type 1 diabetes, respectively (Sharma and Chandola, 2011).

The Clinical Practice Guidelines for the Prevention and Management of Diabetes recommends a target glycosylated hemoglobin $\left(\mathrm{HbA}_{1 \mathrm{c}}\right)$ concentration of $7.0 \%$ or less for all patients with diabetes and, for those in whom it can be safely achieved, a target $\mathrm{HbA}_{1 \mathrm{c}}$ concentration in the normal range, usually $\leq 6.0 \%$ (WHO, 2006). Although nonpharmacologic therapy (e.g., diet, exercise and weight loss) remains a critical component in the treatment of diabetes, pharmacologic therapy is often necessary to achieve optimal glycemic control. Orally administered antihyperglycemic agents (OHAs) can be used either alone or in combination with other OHAs or insulin. Various classes of OHAs are now available that target the different pathophysiologic factors contributing to diabetes: $\alpha$-glucosidase inhibitors to delay intestinal carbohydrate absorption (Lebovitz, 1997; Inzucchi, 2002; Bayraktar et al., 1996), biguanides to target hepatic insulin resistance (Bailey and Turner, 1996; Kirpichnikov et al., 2002; Zhou et al., 2001; Holmes et al., 1999; Salpeter et al., 2004), insulin secretagogues to increase pancreatic insulin secretion (Klepzig et al., 1999; Lebovitz, 2001; Strom et al., 2003; Hatorpe, 2002; McLeod, 2004), insulin sensitizers or thiazolidinediones which function as ligands for the peroxisome proliferator-activated receptor gamma (PPAR $\gamma)$ to target adipocyte and muscle insulin resistance (Lister et al., 1999; Fine good et al., 2001; Bell, 2003; Bakris et al., 2003; Herz et al., 2003; Nesto et al., 2003; Kelly et al., 1999; Lee et al., 2003), and intestinal lipase inhibitor or orlistat to inhibit fat absorption and promote weight loss in obese patients (Guerciolini, 1997; Hollander et al., 1998; Hanefeld and Sachse, 2002; Kelley et al., 2002).

Despite excellent potencies, these synthetic antidiabetic drugs had presented unwanted therapeutic profiles, marked by fluid retention, hypoglycemia at higher doses, liver problems, lactic acidosis, weight gain and potential cardiac hypertrophy. There is also evidence that hyperglycaemia per se has deleterious effects on beta cell function and insulin action (glucotoxicity). Thus, a concerted effort to search more effective drugs for T2DM has become the need of the time in terms of efficacy as well as safety due to the undesirable side effects of synthetic drugs.

Over the past 25 years, $50 \%$ of prescription drugs have been developed from natural products and their derivatives. These medicines have emerged as unique, safe, effective, and relatively inexpensive remedies producing minimal or no side effects with tall claims of efficacy as add on therapy (Heinrich et al., 2012). Herbal drugs with antidiabetic activity can be classified into four categories according to their mode of action The first group has insulinomimetic effect and includes plant like Momordica charantia (bitter gourd) (Grover and Yadav 2004). Second group acts on the $\beta$-cells to increase the production of insulin and include plants like Allium cepa (onion) and Pterocarpus marsupium (Vijaysaar) (Grover and Vats, 2001). The third one enhances glucose utilization in diabetic patients and includes plants like Gingiber officinale (ginger), Cyamospsis 
tetragonalobus (Gower plant) and Grewia asiatica (phalsa). They increase the viscosity of gastrointestinal contents, slow gastric emptying and act as a barrier to diffusion (Grover and Vats, 2001).

Fourth group act by miscellaneous mechanisms and include plants like Euphorbia prostrata, Fumaria parvia, Panax ginseng and Phyllanthus embelica. They may alter the fiber content and thereby altering the rate and speed of absorption of glucose from the gut (Grover and Vats, 2001). The isolation and formulation of active constituents from these plants along with their pharmacological and toxicological evaluation are the need of the modern therapeutics.

Pallab Das Gupta and Amartya De (2012) have compiled some herbal plants and their active ingredients which play an important role in the management of diabetes mellitus. The antidiabetic properties of Bitter melon (Momordica chantrantia), Fiery costus (Costus igneus), Dendelium (Taraxacum officinale), French Lilac (Golega officinalis), Termeric (Curcuma longa), Bael (Aegle marmelus), Amla (Emblica officinalis), Fenugreek (Trigonella foenumgracum), Ginseng (Panax ginseng), Nayantara (Catharanthus roseus), Neem (Azadirachta indica), Cinnamon (Cinnamomum zeylanicum), black berry (Rubus fruticosus) etc. have been greatly illustrated (Shukla, 2000; Wadkar, 2008; Rakesh et al., 2009; Zhijun Song et al., 1997; Mushtaq Ahmad et al., 2009; M.UpendraRao, 2010; Kavishankar, 2011; Suresh Kumar et al., 2012; Manisha Modak, 2007 etc.)

Ocimum sanctum of family Labiatae (Lamiaceae) is indigenous to the tropical regions of Asia and the America and wildly cultivated in India.
Leading phytochemical compounds in holy basil leaf include eugenol (volatile oil), ursolic acid (triterpenoid) and rosmarinic acid (phenylpropanoid). The leaf of OS contains $0.7 \%$ volatile oil comprising about $71 \%$ eugenol and $20 \%$ methyl eugenol. The oil also contains carvacrol and sesquiterpine hydrocarbon caryophyllene. Fresh leaves and stem of OS extract yielded some phenolic compounds (antioxidants) such as cirsilineol, circimaritin, isothymusin, apigenin and rosameric acid and appreciable quantities of eugenol. Two flavonoids, viz., orientin and vicenin from aqueous leaf extract of OS have been isolated ursolic acid, apigenin, luteolin, apigenin-7-Oglucuronide, luteolin-7-O glucuronide, orientin and molludistin have also been isolated from the leaf extract. OS also contains a number of sesquiterpenes and monoterpenes viz., bornyl acetate, $\alpha$ elemene, neral, $\alpha$ - and $\beta$-pinenes, camphene, campesterol, cholesterol, stigmasterol and $\beta$ -sitosterol (Indian Herbal Pharmacopoeia, 2012). Other active compounds include caryophyllene and oleanolic acid. Seeds contain fixed oiks having linoleic acid and linolenic acid. Nutritional components include vitamins $\mathrm{A}$ and $\mathrm{C}$; minerals calcium, iron and zinc; as well as chlorophyll. It contains no caffeine or other stimulants. Holy basil is highly aromatic and different varieties may smell and taste of peppermint, cloves, licorice or lemon. The clove-like odor comes from its high eugenol content. Eugenol is a phenolic compound and major constituent of essential oils extracted from different parts of Tulsi plant. Ocimum sanctum known as 'Tulsi' in hindi and 'Holy Basil' in English, is an erect softy hairy aromatic herb or under shrub found throughout India. Two types of Ocimum sanctum are met within cultivation: (i) Tulsi plants with green leaves known as Sri Tulsi \& (ii) Tulsi plants with purple leaves known as Krishna Tulsi. Ocimum sanctum is held 
sacred by Hindus and is used as medicinal plants in day to day practice in Indian homes for various ailments.

The hypoglycemic effects of Ocimum sanctum extract on mice diabetic models has not been evaluated so far and hence the present investigation was undertaken.

\section{Materials and Methods}

Methanol extract of Ocimum sanctum Linn. (Lamiaceae) was used for assaying hypoglycemic activities in Streptozotocin induced mice diabetic models. The plant Ocimum sanctum was collected from campus of Patna Science College, Patna and identified following relevant monographs of Indian Pharmacopoeia (2012). Freshly harvested plant materials (root, stem, leaves and flowers) were washed under running tap water, blotted with filter paper and was dried in the shade at room temperature. The dried plant sample $(2.6 \mathrm{~kg})$ was then soaked with absolute methanol under reflux condition for the methanolic extract preparation. The sample was then homogenized with extraction buffer and the supernatant collected after three rounds of extraction. The solvent was evaporated under reduced pressure in a rotary evaporator at $40{ }^{\circ} \mathrm{C}$. To this thick paste colloidal silicon dioxide was added and dried in vacuum tube dryer. The obtained methanol extract was stored in deep freezer at $-20^{\circ} \mathrm{C}$ until further test.

Significant insights into the etiology of diabetes in human have been gained from the study of animal models. The albino mouse is an excellent model for study of human diabetes. Therefore all mice used in this study were in the albino genetic background. Adult albino mice weighing around 17-20 gram with $6.5 \pm 0.5 \mathrm{~cm}$ length are selected for experiments. The mice were housed in shoe-box type cages under good hygienic conditions in the departmental animal house during experimental period. The mice were allowed to acclimatize for 15 days in an environmentally controlled room under standard environmental conditions $\quad\left(21 \pm 2^{\circ} \mathrm{C}, \quad 55 \pm 5 \%\right.$ Relative humidity, 12 hr Light: Dark cycle).

The mice were fed on diet consisted of wheat grains-1 Kg, Choker wheat-250gm, Gram grains-250gm, Maize grains-250gm, Soybean grains-250gm, Sundrop oil-50gm, Milk powder-2 table spoon and Jaggery$50 \mathrm{gm}$. This diet provided carbohydrate $48.3 \%$, crude protein $23.5 \%$,crude fat $5.9 \%$ crude ash $5.9 \%$ and crude fibre $3.9 \%(\mathrm{~W} / \mathrm{W})$.

In each cage one pellet of feed per mice was given. The diet was palatable to the animal as evidenced by feeding success. It has been observed that an adult mice normally intakes 4 to 5 gram of diet per day. The daily food consumption of the mice varied depending upon the physiological and health status of the mice as well as the environmental temperature. The consumption of food increased considerably when the mice were pregnant or at lactating stage and decreased considerably with the dose-duration and increased temperature in summer.

The animal model for the present study was based on multiple administration of low dose of freshly prepared streptozotocin (STZ). For induction of diabetes, initially the normal mice were kept 24 hours without food and water. The weight of normal mice was determined. Diabetes was induced by multiple intra-peritoneal injection of freshly prepared STZ solution in $0.05 \mathrm{M}$ sodium citrate $(\mathrm{pH} 4.5)$ at the dose of $35 \mathrm{mg} / \mathrm{kg}$ body weight followed by an hour of fasting. The mice were then allowed to access the respective food and water ad libitum. Mice with fasting blood glucose level of $200 \mathrm{mg} / \mathrm{dl} \quad(7.8 \mathrm{mmol} / \mathrm{l})$ or higher were 
considered to be diabetic and were used in the study. A parallel set of control mice (non-diabetic) were injected with citrate buffer only.

The mice were grouped into five categories viz., Normal control (NC), Diabetic Control (DC), Diabetic Treated $\left(\mathrm{DT}_{150}\right)$, Diabetic Treated $_{250}$ ) and Diabetic Treated (DT ${ }_{\text {PGZ }}$ ). NC received only citrate buffer solution. DC group was STZ induced which received citrate buffer only. $\mathrm{DT}_{150}$ and $\mathrm{DT}_{250}$ received $150 \mathrm{mg} / \mathrm{Kg}$ and $250 \mathrm{mg} / \mathrm{Kg}$ body weight of methanol extract respectively. $\mathrm{DT}_{\mathrm{PGZ}}$ received Pioglitazone at a dose of $2 \mathrm{mg} / \mathrm{Kg}$ of body weight. All the mice were fed with common pellet diets for 2 weeks after arrival, and then randomly divided into two groups. One group continued to receive common pellet diets and constituted the normal group; the other was fed with diets high in fat and fructose, in order to induce type- 2 diabetes. All the mice had free access to food and water.

For the experiment, the mice were divided into five groups having six mice in each group: DC group (diabetic control mice), NC group (non-diabetic control mice) and three DT group (diabetic mice treated with two different doses of extract as well as Pioglitazone/ kg body weight). Body weights were recorded weekly during the experimental period. Treatment with extracts was started after one week of STZ treatment, which was considered as the $1^{\text {st }}$ day of treatment. Blood samples were taken after $8 \mathrm{hrs}$ fasting from the retro-orbital sinus vein prior to the administration of test substances or the buffer and 4 weeks after the treatment under mild ether anesthesia and allowed to clot for 30 minutes at room temperature. Blood samples were centrifuged at $3000 \mathrm{rpm}$ for 20 minutes. Serum was separated and stored at $-20^{\circ} \mathrm{C}$ until biochemical estimations were carried out.
Data were statically analyzed by mean \pm S.E and by one-way ANOVA.

The results related to body weight change and blood glucose level in $\mathrm{mmol} / \mathrm{l}$ in mice during present course of investigation have been presented in Table- 1 and 2 .

\section{Results and Discussion}

The whole plant extract of Ocimum sanctum has been reported to be effective in alleviating diabetes mellitus through its antioxidant and insulin- potentiating activities (Okoli et al., 2010). In the present investigation the effect of methanol extract of Ocimum sanctum on body weight of mice was studied. The results clearly indicated that the diabetic control (DC) mice presented a significant lowering of body weight $(p<0.001)$ when compared with the normal control (NC) mice (Table- $1 \&$ Fig. 1). A significant gain in body weight was observed in the treated groups of diabetic mice $\left(\mathrm{DT}_{150}\right.$ and $\mathrm{DT}_{250}$ ) as compared to the $\mathrm{DC}$ ones. The $\mathrm{DT}_{150}$ and $\mathrm{DT}_{250}$ group showed an increase of $28 \%$ and $39 \%$ in body weight respectively after 15 days of treatment. Contrary to this, $\mathrm{DT}_{\mathrm{RGZ}}$ group mice showed an increase of $50 \%$ in body weight after 15 days of treatment (Table-1\& Fig. 1).

The changes in the blood glucose levels before and after receiving the treatment in normal and diabetic mice have been presented in Table -2 and Figure 2. As expected, the DC mice showed a significantly $(p<0.001)$ higher level of glucose $(+279 \%)$, when compared with their normal control counterparts. Diabetic mice of both of the groups ( $\mathrm{DT}_{150}$ and $\mathrm{DT}_{250}$ ) showed a reduction in glucose levels, when compared to the DC ones; nevertheless, the reduction was particularly evident in the $\mathrm{DT}_{250}$ mice $(-44 \% ; p<0.001)$. When 
compared, the glucose levels of the $\mathrm{DT}_{250}$ versus the DC group mice during the 4-week treatment program, a significant lower value in the first was also found $(-45 \% ; p<0.001)$ respectively (Table-2\& Fig. 2). Nevertheless, this decline in the glucose levels was less evident in the $\mathrm{DT}_{150}$ mice $(-38 \%)$ than in the $\mathrm{DT}_{250}$ mice. In contrast to this, $\mathrm{DT}_{\mathrm{PGZ}}$ group mice showed almost $67 \%$ decline in glucose level after 4-weeks of treatment program (Table -2\& Fig. 2).

Phytochemicals from natural products possess potent antioxidant activity that are capable of prevention of the onset and/or progression of many human diseases by counteracting reactive oxygen species (ROS) (Palasuwan et al., 2005; Cai et al., 2006; Bouayed et al., 2007; Liu et al., 2007). An alcoholic extract of $O$. sanctum was found to reduce significantly the blood sugar in normal mice and in STZ induced diabetes mice. In normal mice, administration of $O$. sanctum $200 \mathrm{mg} / \mathrm{kg}$ body weight reduced the blood sugar by 34.5 percent and to 47.4 percent at the concentration of $1000 \mathrm{mg} / \mathrm{kg}$ by weight at 1 hour. However at 6th hour, values are almost similar to normal value. Continuous administration of the drug produced significant reduction in normal blood sugar in mice, which on 15th day was also found to reduce the blood sugar in streptozotocin diabetic mice. In short term experiment, drug was found to reduce the blood sugar at 4th hour by 6.07 percent at dose level of $200 \mathrm{mg} / \mathrm{kg}$ by weight and 18.7 percent at concentration of $1000 \mathrm{mg} / \mathrm{kg}$ by weight. Continuous administration of drug produced significant reduction in blood sugar in streptozotocin diabetic mice. On $15^{\text {th }}$ day values were almost similar to normal in the group taking $1000 \mathrm{mg} / \mathrm{kg}$ by weight. Plant extract did not produce any toxicity as seen from liver and kidney function test and in hematological parameters. The results indicate potential antidiabetic action of $O$. sanctum (Raphael et al., 2000).

Diabetes has a significant impact on the health, quality of life and life expectancy of patients as well as healthcare expenditure. With increasing incidence and mortality from its complications, prompt and adequate glycemic control in diabetes is paramount if management can meaningfully improve the quality of life and increase life expectancy (Nyenwe et al., 2011).

Several studies to test new drugs with potential antidiabetic activity were used in animal models of streptozotocin (STZ)induced diabetes (Fröde and Madeiros, 2008). Although none of the chemicallyinduced diabetic models can reproduce the complexity of the human disease, they can be helpful to understand at least some aspects of the potential bioactivities of natural or synthetic products. We used diabetic albino mice induced by STZ (35 $\mathrm{mg} / \mathrm{kg}$ body wt.), which was sufficient to induce a stable state of diabetic condition in this animal species.

Induction of diabetes with streptozotocin is associated with a characteristic loss of body weight, which is probably due to muscle wasting. In the present investigation there was a significant weight loss in the vehicle treated diabetic mice, where as treatment with the $O$. sanctum extract at three doses showed improvement in their body weight, indicating that the methanolic extract of $O$. sanctum had beneficial effect in preventing loss of body weight of diabetic mice. The probable mechanism of this benefit is due to its effect in controlling muscle wasting, i.e., by reversal of antagonism. The metabolic disturbances were corrected after the plant extract was administered at the two different dose of 150 and $250 \mathrm{mg} / \mathrm{kg}$ body weight for four weeks as shown by a reduction in 
biochemical parameters in diabetic mice treated with plant extract. This result is in accordance with Lenzen S. (2008) and Chung et al., (2003). They have found that multiple low dose of STZ sufficiently induce stabilized acute diabetes in which there is a progressive deterioration in the glucose tolerance and insulin secretion after the STZ injection. It ultimately causes increased oxidative stress, which play an important role in the pathogenesis of various complications. The present findings are also in accordance with Santwana Rani and Baidyanath Kumar (2015) who found a more or less similar results of Phyllanthus niruri methanol extract on Streptozotocin induced mice diabetic models. Atul et al., (2014) have found the efficacy of Trigonella foenum gracum and Costus igneus in the management of type- 2 diabetes mellitus in 11 subjects.

Oral administration of Ocimum sanctum extract led to marked lowering of blood sugar in normal, glucose fed hyperglycemic and streptozotocin-induced diabetic rats (Chattopadhyay, 1993). A randomized, placebo-controlled, cross over single blind human trial indicated a significant decrease in fasting and postprandial blood glucose levels by $17.6 \%$ and $7.3 \%$, respectively. Urine glucose levels showed a similar trend (Agrawal, 1996). Further, OS has aldose reductase activity, which may help in reducing the complications of diabetes such as cataract, retinopathy, etc (Halder, 2003).

At present, several drugs are available for the management of hyperglycemia but they are expensive and possess side effects also. Therefore, search for a suitable alternative is continued. For the developing countries herbal plants may be the most attractive target for their availability, low cost and better safety margin. The hypoglycemic activity of Ocimum sanctum L. has attracted many researchers to prove it scientifically and to investigate its mechanisms of actions. Hence, in the present study, the two defined doses of methanolic extract of whole plant of $O$. sanctum have been investigated for their antidiabetic potential.

Chronic hyperglycaemia in diabetes is a risk factor constantly fuelled by postprandial elevation of blood glucose. Control of postprandial hyperglycemia in diabetes is of great importance due to its close relation to the risk of micro and macro-vascular complications and death (Nyenwe et al., 2011). In the present investigation, experimental evaluation of the hypoglycemic potentials of $O$. sanctum has shown that the higher dose of extract (250 $\mathrm{mg} / \mathrm{kg}$ body wt.) suppress postprandial rise in blood glucose levels more effectively than lower dose of extract $(150 \mathrm{mg} / \mathrm{kg}$ body wt.) which is the index of effectual glycemic control. It may be due to alteration in the fiber content as well as phytochemical interactions which thereby altering the rate and speed of absorption of glucose from the gut. These favorable effects of $O$. sanctum extract may be attributed to higher affinity and synergistic action of their phytochemicals on multiple targets including PPAR- $\gamma$ activation and DPP-IV inhibition which may therefore regulate the hyperglycemia, lipogenesis and hypertriglyceridemia associated with diabetes (Shimizu et al., 2003; Barnett, 2006).

In the hypoglycemic activity studies of methanol extract, daily oral administration of the extract for 28 days produced a gradual but sustained reduction in blood glucose levels in diabetic treated mice. Streptozotocin causes hyperglycaemia and glucose intolerance or syndromes similar to either type 1 or type 2 diabetes (Frode and Medeiros, 2008). Effective and sustained reduction in blood glucose levels of treated diabetic mice by the extract indicates that it may be useful in overt cases of diabetes. 
Table.1 Showing body weight changes in mice during and after treatment with methanol extract of $O$. sanctum

\begin{tabular}{|l|l|l|l|}
\hline \multirow{2}{*}{ Non Diabetic Normal Control (NC) } & Day 0 & Day7 & Day15 \\
\cline { 2 - 4 } & $\mathbf{1 9 . 9 8} \pm \mathbf{2 . 8 6}$ & $\mathbf{2 1 . 8 0} \pm \mathbf{2 . 4 1}$ & $\mathbf{2 4 . 8 5} \pm \mathbf{2 . 2 6}$ \\
\hline \multicolumn{3}{|c|}{ Diabetic Mice } \\
\hline Diabetic Control $(\mathrm{DC})$ & $11.70 \pm 1.15$ & $09.50 \pm 0.95$ & $7.67 \pm 1.22$ \\
\hline O. sanctum extract $(150 \mathrm{mg} / \mathrm{Kg})\left(\mathrm{DT}_{150}\right)$ & $11.71 \pm 2.03^{*}$ & $12.11 \pm 1.67^{*}$ & $13.75 \pm 1.54^{*}$ \\
\hline O. sanctum extract $(250 \mathrm{mg} / \mathrm{Kg})\left(\mathrm{DT}_{250}\right)$ & $11.68 \pm 1.63^{*}$ & $12.75 \pm 2.37^{*}$ & $14.85 \pm 2.65^{*}$ \\
\hline Pioglitazone $(2 \mathrm{mg} / \mathrm{Kg})\left(\mathrm{DT} \mathrm{PGZ}_{\mathrm{PGZ}}\right.$ & $11.70 \pm 3.74^{*}$ & $14.85 \pm 3.91^{*}$ & $16.24 \pm 1.85^{*}$ \\
\hline
\end{tabular}

*significant as compared to control; $\mathbf{n}=6$ in each group

Table.2 Showing effects of different doses of $O$. sanctum extract and Pioglitazone on blood glucose levels in mice

\begin{tabular}{|l|c|c|c|c|c|}
\hline \multirow{2}{*}{ Mice Groups } & \multicolumn{6}{|l|}{ Blood glucose levels in (mmol/I) in four different weeks } \\
\cline { 2 - 6 } & Pretreatment & Post-treatment & \multicolumn{3}{l|}{} \\
\cline { 2 - 6 } & $\mathbf{0}$ & $\mathbf{1}$ & $\mathbf{2}$ & $\mathbf{3}$ & $\mathbf{4}$ \\
\hline Normal control (NC) & $3.95 \pm 0.13^{* *}$ & $4.07 \pm 0.14^{* *}$ & $4.06 \pm 0.25^{* *}$ & $4.05 \pm 0.16^{* *}$ & $3.99 \pm 0.19^{* *}$ \\
\hline Diabetic control (DC) & $14.92 \pm 1.55^{*}$ & $14.91 \pm 1.48^{*}$ & $14.78 \pm 1.59^{*}$ & $14.96 \pm 1.49^{*}$ & $14.94 \pm 1.48^{*}$ \\
\hline $\begin{array}{l}\text { O. sanctum extract }(150 \mathrm{mg} / \mathrm{Kg}) \\
\mathrm{DT}_{150}\end{array}$ & $14.95 \pm 1.45$ & $13.04 \pm 1.18^{*}$ & $10.65 \pm 2.09^{* *}$ & $9.65 \pm 1.28^{* *}$ & $9.25 \pm 1.79^{* *}$ \\
\hline $\begin{array}{l}\text { O. sanctum extract }(250 \mathrm{mg} / \mathrm{Kg}) \\
\mathrm{DT}_{250}\end{array}$ & $14.65 \pm 1.56$ & $11.86 \pm 1.38^{* *}$ & $9.55 \pm 1.28^{* *}$ & $8.20 \pm 1.74^{* *}$ & $8.12 \pm 1.28^{* *}$ \\
\hline Pioglitazone $(2 \mathrm{mg} / \mathrm{Kg}) \mathrm{DT}_{\mathrm{PGZ}}$ & $15.03 \pm 1.49$ & $9.84 \pm 1.48^{* *}$ & $5.57 \pm 1.28^{* *}$ & $4.97 \pm 1.35^{* *}$ & $4.94 \pm 0.97^{* *}$ \\
\hline
\end{tabular}

${ }^{*} p<0.05$ as compared with normal control. ${ }^{* *} p<0.001$ as compared with diabetic control.

Fig.1 showing change in body weight of mice after administration of O. sanctum extract and PGZ

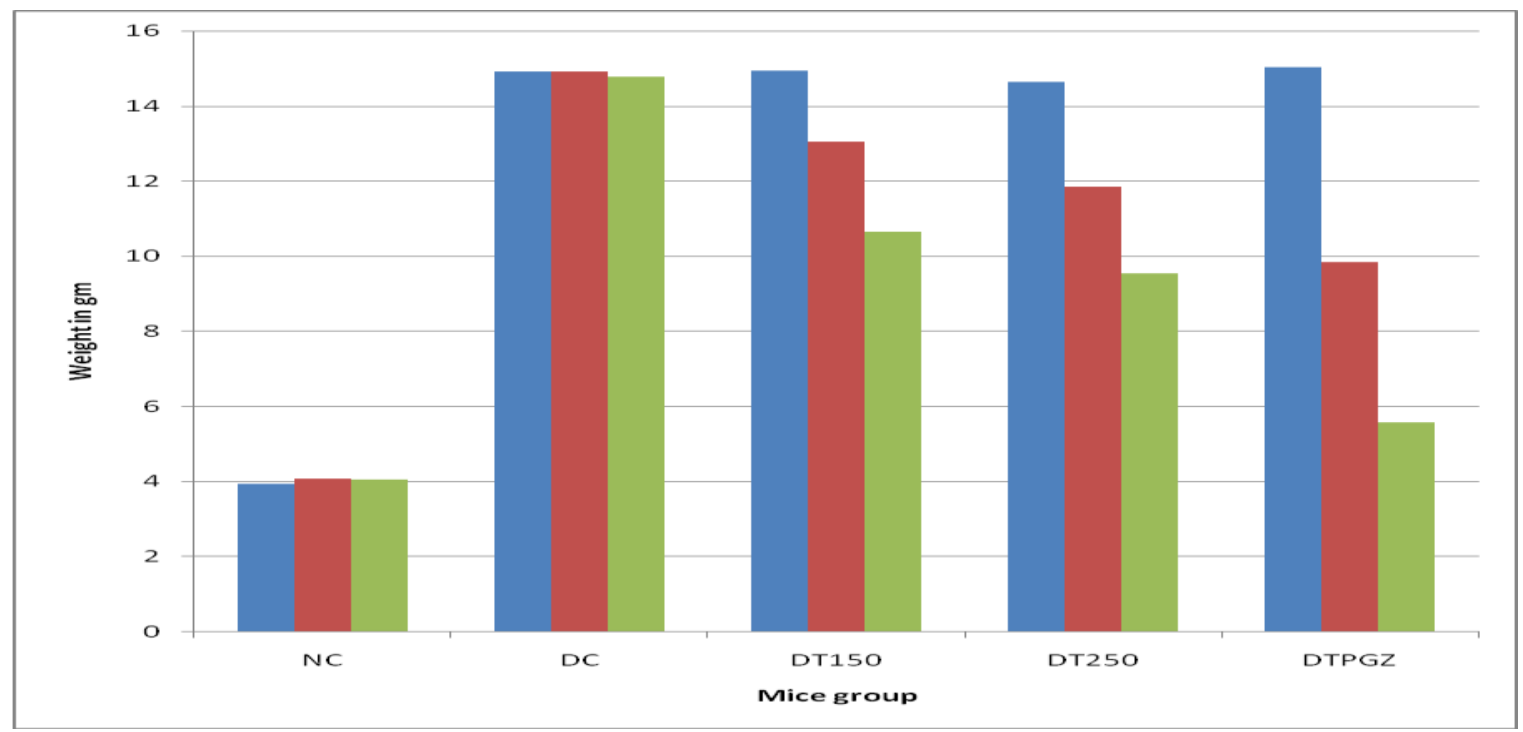


Fig.2 showing effects of different doses of $O$. sanctum extract and Pioglitazone on blood glucose levels in mice before and four weeks after administration

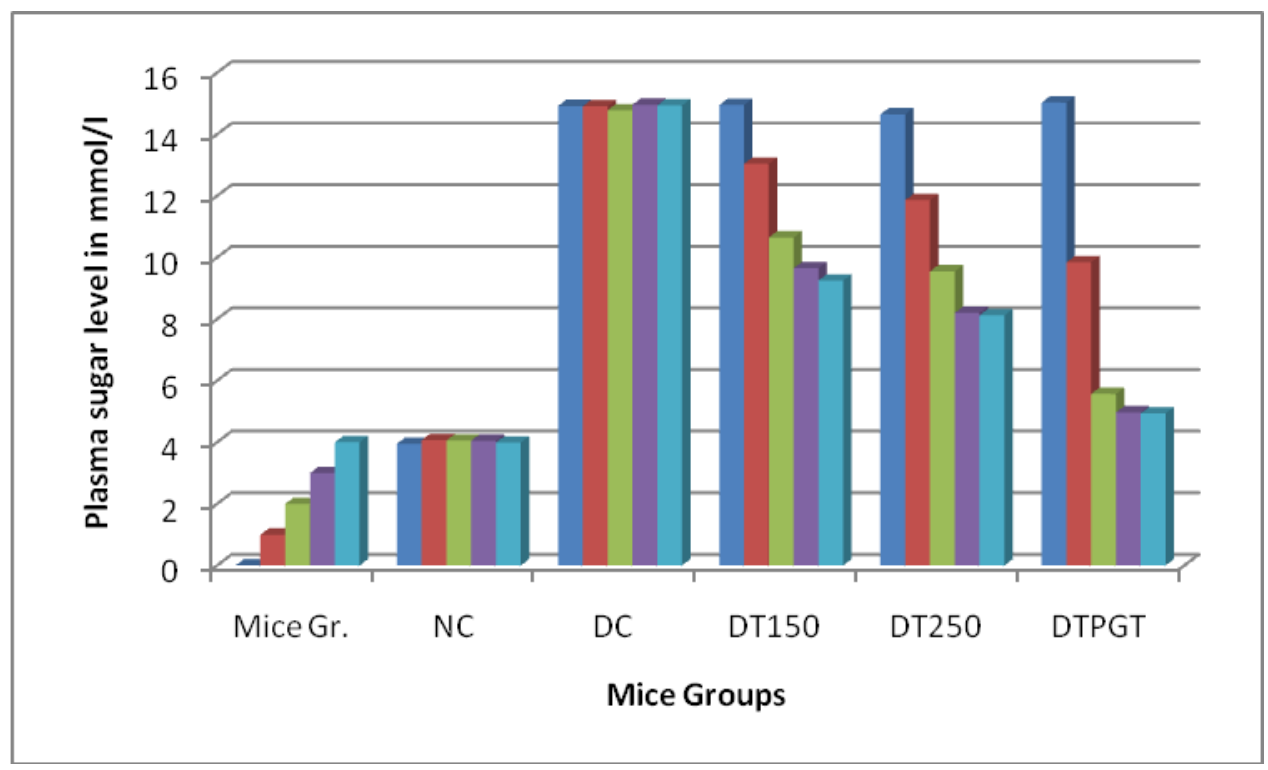

Treatment with the two doses of extract also reduced mortality of diabetic mice from hyperglycaemia and prolonged their survival. In the present study, some of the diabetic non-treated control animals all died on day 10 post-induction of diabetes whereas the extract-treated group survived beyond the period of the experiment. Effective control of blood glucose level is a key step in preventing and reversing diabetic complications, and improving the quality of life of diabetic patients (Bavarva and Narasimhacharya, 2008). Hence, chronic administration of the extract may cause a progressively sustained reduction in hyperglycaemia known to reduce the risk of complications associated with the disease.

From the results it can be concluded that the Ocimum sanctum whole plant methanol extract is antidiabetic in nature due to the presence of different types of active phytochemicals, which may have different mechanism of action. The combination of these phytochemicals, therefore, might be beneficial as hypoglycemic agents. The $O$. sanctum plant extract might be considered as a safe supplementary therapy for long- term and effective management of diabetic patients.

\section{Acknowledgement}

The authors are thankful to Dr. Baidyanath Kumar, Visiting Professor, Department of Biotechnology, Patna Science College, ,Pa.tna (PU), for providing necessary suggestion for the preparation of this research article.

\section{References}

Agrawal, P., Rai, V., Singh, R.B. 1996. Int. J. Clin. Pharmacol. Ther., 34: 406.

Anoop Misra and Naval, K., Vikram. 2002. Insulin resistance syndrome (metabolic syndrome) and Asian Indians, Curr. Sci., 83(12), 1483- 1496.

Atul Kumar, Baidyanath Kumar and Smita Kumari. 2014. Diabetes Mellitus and its Herbal treatment, Int. J. Biol. Med. Res., (3): 4180- 4185.

Bakalov, V.K., Cooley, M.M., Troendle, J., Bondy, C.A. 2004. The prevalence of 
diabetes mellitus in the parents of women with Turner's syndrome. Clin. Endocrinol., (Oxf) 60: 272.

Bakris, G., Viberti, G., Weston, W.M., Heise, M., Porter, L.E., Freed, M.I. 2003. Rosiglitazone reduces urinary albumin excretion in type II diabetes. J. Hum. Hypertens, 17(1): 7-12.

Bailey, C.J., Turner, R.C. 1996. Metformin. N Engl. J. Med., 334: 574-9.

Barnett, A. 2006. DPP-4 inhibitors and their potential role in the management of type 2 diabetes. Int. J. Clin. Pract., 60(11): 1454-70.

Bavarva, J.H., Narasimhacharya, A.V.R.L. 2008. Antihyperglycemic and hypolipidemic effects of Costus speciosus in alloxan induced diabetic rats. Phytother. Res., 22: 620-626.

Bayraktar, M., Van Thiel, D.H., Adalar, N. 1996. A comparison of acarbose versus metformin as an adjuvant therapy in sulfonylurea-treated NIDDM patients. Diabetes Care, 19: 252-4.

Beck- Nielsen, H. and Groop, L.C. 1994. J. Clin. Invest., 94: 1714- 1721.

Bell, D.S.H. 2003. Beta-cell rejuvenation with thiazolidinediones. Am. J. Med., 115: 20S-3S.

Bouayed, J., Piri, K., Rammal, H., Dicko, A., Desor, F., Younos, C., Soulimani, R. 2007. Comparative evaluation of the antioxidant potential of some Iranian medicinal plants. Food Chem., 104(1): 364-368

Cai, Y.Z., Mei, S., Jie, X., Luo, Q., Corke, H. 2006. Structure-radical scavenging activity relationships of phenolic compounds from traditional Chinese medicinal plants. Life Sci., 78(25): 28722888.

Chattopadhyay, R.R. 1993. Indian J. Exp. Biol., 31: 891-893.

Chang, C.C., Lien, Y.C., Liu, K.C., Lee, S.S. 2003. Lignans from Phyllanthus urinaria. Phytochem., 63: 825-833.
Elder, D.A., Kaiser- Roger, K., Aylsworth, A.S. and Calikoglu. 2001. Type I diabetes mellitus in a patient with chromosome 22q11.2 deletion syndrome. Am. J. Med. Genet., 101(1): 17- 19.

Frode, T.S., Medeiros, Y.S. 2008. Animal models to test drugs with potential antidiabetic activity. J. Ethnopharmacol., 115: 173-183.

Finegood, D.T., McArthur, M.D., Kojwang, D., Thomas, M.J., Topp, B.G., Leonard, T., et al. 2001. Beta-cell mass dynamics in Zucker diabetic fatty rats: rosiglitazone prevents the rise in net cell death. Diabetes, 50(5): 1021-9.

Guerciolini, R. 1997. Mode of action of orlistat. Int. J. Obes., 21(suppl 3): S12S23.

Grover, J.K., Yadav, S.P. 2004. "Pharmacological actions and potential uses of Momordica charantia: A review".J. Ethnopharmacol., 93(1): 123-132.

Grover, J.K., Vats, V. 2001. Shifting paradigm: From conventional to alternative medicines an introduction on traditional Indian medicines. Asia Pacific Biotech News, 5: 28-32.

Halder, N., Joshi, N., Gupta, S.K. 2003. J. Ethnopharmacol., 86(1): 113-116.

Nair, A.G.R., Gunasegaran, R., Joshi, B.S. 1982. Indian J. Chem., 21B, 979.

Holmes, B.F., Kurth-Kraczek, E.J., Winder, W.W. Chronic activation of 5'-AMPactivated protein kinase increases GLUT-4, hexokinase, and glycogen in muscle. J. Appl. Physiol., 87: 1990-5.

Hatorpe, V. 2002. Clinical pharmacokinetics and pharmacodynamics of repaglinide. Clin Pharmacokinet., 41: 471-83.

Herz, M., Johns, D., Reviriego, J., Grossman, L.D., Godin, C., Duran, S., et al. 2003. A randomized, double-blind, placebo-controlled, clinical trial of the effects of pioglitazone on glycemic 
control and dyslipidemia in oral antihyperglycemic medication-naive patients with type 2 diabetes mellitus. Clin. Ther., 25(4): 1074-95.

Hollander, P.A., Elbein, S.C., Hirsch, I.B., Kelley, D., McGill, J., Taylor, T., et al., Role of orlistat in the treatment of obese patients with type 2 daibetes. Diabetes Care, 21(8):1288-94.

Hanefeld, M., Sachse, G. 2002. The effects of orlistat on body weight and glycaemic control in overweight patients with type 2 diabetes. Diabetes Obes. Metab., 4: 415-23.

Heinrich, M., Barnes, J., Gibbons, S., Williamson EM. Fundamentals of Pharmacognocy and Phytotherapy. Churchill Livingston, Elsevier Sci., Ltd, U.K 2012.

Inzucchi, S.E. 2002. Oral antihyperglycemic therapy for type 2 diabetes. JAMA, 287: 360-72.

Iyer, R., Upasani, S. and Baitule, M. N. 2000. ibid, 50, 519, Suppl. 1.

Kelly, I.E., Hans, T.S., Walsh, K., Lean, M.E. Effects of a thiazolidinediones compound on body fat and fat distribution of patients with type 2 diabets. Diabetes Care, 22: 288-93.

Kelley, D.E., Bray, G.A., Pi-Sunyer, F.X., Klein, S., Hill, J., Miles, J., et al., Clinical efficacy of orlistat therapy in overweight and obese patients with insulin-treated type 2 diabetes: a 1-year randomized controlled trial. Diabetes Care, 25 (6): 1033-41.

Knowler, W.C., Barrett-Connor, E., Fowler, S.E., Hamman, R.F., Lachin, J.M., Walker, E.A., et al; Diabetes Prevention Program Research Grou9. Reduction in the incidence of type 2 diabetes with lifestyle intervention or metformin. $N$ Engl J Med 2002; 346(6):393-403.

Klepzig, H., Kober, G., Matter C, Luus H, Schneider $\mathrm{H}$, Boedeker $\mathrm{KH}$, et al., Sulfonylureas and ischaemic preconditioning: a double-blind, placebocontrolled evaluation of glimepiride and glibenclamide. Eur J 1999; 20(6): 403-5.

Kirpichnikov, D., McFarlane SI, Sowers JR. Metformin: an update. Ann Intern Med 2002; 137:25-33.

King, H., Aubert, R. E. and Herman, W. H. Diab. Care, 21, 1414- 1431.

Lin, Y., Sun Z. Current views on type 2 diabetes. J Endocrinol 2010; 204: 1-11.

Lebovitz, H.E. Alpha-glucosidase inhibitors. Endocrinol Metab Clin North Am 1997; 26: 539-51.

Lebovitz, H.E. Oral therapies for diabetic hyperglycemia. Endocrinol Metab Clin North Am 2001; 30;909-33.

Lee, C.H., Olson, P., Evans. R.M. Minireview: lipid metabolism, metabolic diseases, and peroxisome proliferatorsactivated receptors. Endocrinology 2003; 144: 2201-2207.

Lister, C.A., Moore GBT, Piercy V, et al., Rosiglitazone, but not metformin or glibenclamide, improves glycaemic control and increases islet insulin content. Diabetologia 1999; $\quad$ 42(suppl 1):A150.

Lenzen, S. The mechanisms of alloxan- and streptozotocin- induced diabetes. Diabetologia 2008; 51 (2) : 216-26.

Liu, X., Dong, M., Chen, X., Jiang M, Lv X, Yan G. Antioxidant activity and phenolics of an endophytic Xylaria sp. from Ginkgo biloba. Food Chem 2007; 105(2): 548-554.

McLeod, J.F. Clinical pharmacokinetics of nateglinide. Clin Pharmacokinet 2004; 43:97-120.

Misra, A., Pandey, R. M., Rama Devi, J., Sharma, R., Vikram, N. K. and NidhiKhanna (2001): Int. J. Obesity, 25, 1- 8.

Mohan, V., Shanthirani, S., Deepa, R., Premalatha, G., Sastry, N. G. and Saroja, R (2001): Diab. Med., 18, 280- 287. 
Mokhtari, D, Myers JW, Welsh N. APK kinase kinase- 1 is essential for cytokineinduced c-Jun NH2-terminal kinase and nuclear factor $-\kappa \mathrm{B}$ activation in human pancreatic islet cells. Diabetes 57:18961904.

Nesto, R.W., Bell, D., Bonow, R.O., Fonseca, V., Grundy SM, Horton ES, et al; American Heart Association; American Diabetes Association. Thiazolidinedione use, fluid retention, and congestive heart failure: a consensus statement from the American Heart Association and American Diabetes Association. Circulation, 108(23): 29418.

Nyenwe, E.A., Jerkins, T.W., Umpierrez, G.E., Kitabchi AE. Management of type 2 diabetes: evolving strategies for the treatment of patients with type 2 diabetes. Metabolism 2011; 60:1-23.

Neve, B., Fernandez-Zapico ME, Ashkenazi-Katalan V, Dina C, Hamid YH, Joly E, Vaillant E, Benmezroua Y, Durand E, Bakaher N, Delannoy V, Vaxillaire M, Cook T, Dallinga-Thie GM, Jansen H, Charles MA, Clément K, Galan P, Hercberg S, Helbecque N, Charpentier G, Prentki M, Hansen T, Pedersen O, Urrutia R, Melloul D, Froguel P(2005): Role of transcription factor KLF11 and its diabetes-associated gene variants in pancreatic $\beta$ cell function. Proc. Natl. Acad. Sci., USA 102:4807-4812.

Palasuwan, A., Soogarun S, Lertlum T, Pradniwat P, Wiwanitkit V. Inhibition of Heinz body induction in an in vitro model and total antioxidant activity of medicinal Thai plants. Asian Pac $J$ Cancer Prev 2005; 6: 458-463.

Raman Kutty, Soman, C. Rt., Joseph, A., Pisharody, R. and Vijayakumar, K. (2000): Natl. Med. J. India, 13, 287- 292.

Ramachandran, A., C. Snehalata and Vijay Viswanathan (2002): Burden of type 2 diabetes and its comlications- The Indian scenario, Current Sci., 83(12), 14711476.

Rebecca, J., Gardner, Andrew, J. Mungall, Ian Dunham, John, C.K. Barber, Julian P H Shield,I Karen Temple, David O Robinson (1999):Localization of a gene for transient neonatal diabetes mellitus to an $18.72 \mathrm{cR} 3000$ ( $\square 5.4 \mathrm{Mb}$ ) interval on chromosome 6q,J Med Genet., 36: 192196

Raphael, K.R., Sabu, M.C. 2000. Antidiabetic activity of Phyllanthus niruri, Amala research bulletin, 20: 1925.

Reaven, G.M. 1988. Diabetes, 37, 15951607.

Shimizu, S., Ugi, S., Maegawa, H., Egawa K, Nishio Y, Yoshizaki T, Shi K, Nagai Y, Morino K, Nemoto K. Proteintyrosine phosphatase I B as new activator for hepatic lipogenesis via sterol regulatory element-binding protein-1 gene expression. J. Biol. Chem., 278: 430-95.

Strom, B.L., Schinnar, .R, Apter AJ, Margolis DJ, Lautenbah E, Hennessy S, et al., Absence of cross-reactivity between sulfonamide antibiotics and sulfonamide nonantibiotics. $N$ Engl $J$. Med., 349(17): 1628-35.

Salpeter, S., Greyber, E., Pasternak, G., Salpeter, E. Risk of fatal and nonfatal lactic acidosis with metformin use in type 2 diabetes mellitus. [Cochrane review]. In: The Cochrane Library; Issue 4, 2004. Oxford: Update Software

Santwana Rani and Baidyanath Kumar. 2015. Glycemic control efficacy of Phyllanthus niruri. Linn extract in Diabetic Mice model, Int. J. Curr. Microbiol. App. Sci., 4(4): 599-609.

Salgin, B., Amin, R., Yuen K, Williams RM, Murgatroyd P, Dunger DB (2006): Insulin resistance is an intrinsic defect independent of fat mass in women with 
Turner's syndrome. Horm. Res., 65: 6975.

Senée, V., Chelala, C., Duchatelet S, Feng $\mathrm{D}$, Blanc $\mathrm{H}$, Cossec JC, Charon C, Nicolino M, Boileau P, Cavener DR, Bougnères P, Taha, D., Julier, C. 2006. Mutations in GLIS3 are responsible for a rare syndrome with neonatal diabetes mellitus and congenital hypothyroidism. Nat Genet., 38: 682-687.

Song, B., Scheuner, D., Ron D, Pennathur S, Kaufman, R.J. 2008. Chop deletion reduces oxidative stress, improves $\beta$ cell function, and promotes cell survival in multiple mouse models of diabetes. $J$. Clin. Invest., 118: 3378-3389.

Suheir Assady. 2009. Challenges and Prospects for Stem Cell-Based Therapy in Diabetes Mellitus israel medical association world fellowship conference VOL11.

Sharma, H., Chandola, H.M. Prameha in Ayurveda: correlation with obesity, metabolic syndrome, and diabetes mellitus. Part 2--management of Prameha. J. Altern. Complement Med., 17(7): 589-99. The Indian Pharmacopoeia, http://ipc.nic.in

Tuomilehto, J., Lindstrom, J., Eriksson, J.G., Valle, T.T., Hamalainen, H., IlanneParikka, P., et al. Finnish Diabetes Prevention Study Group. Prevention of type 2 diabetes mellitus by changes in lifestyle among subjects with impaired glucose tolerance. $N$ Engl. J. Med., 344(18): 1343-50.

Torben Hansen. 2002. Genetics of Type 2 diabetes, Curr. Sci., 83(12), 1477- 1482.

Umesh Masharani and John, H. Karam. 2003. Diabetes Mellitus and Hypoglycemia, In Current Medical Diagnosis and Treatment, Edited by Lawrence M. Tierney, Jr. Stephen J. MCPhee and Maxine A. Papadakis, Lange Medical Book/ McGraw- Hill, International Edition, pp. 1152- 1198.

Verma, N.P.S. and Madhu, S.V. 2000. Diab. Res. Clin. Prac., 50, 615, Suppl. 1.

Vladimir, K. Bakalov, Clara Cheng, Jian Zhou and Carolyn. 2009. XChromosome Gene Dosage and the Risk of Diabetes in Turner Syndrome J. Clin. Endocrinol. Metab., 94(9): 3289-3296.

World Health Organization. 2006. Diabetes Fact Sheet Number 312, www.who.org Zhao, L., Guo, M., Matsuoka, T.A., Hagman, D.K., Parazzoli, S.D., Poitout, V., Stein, R. 2005. The islet $\beta$ cellenriched MafA activator is a key regulator of insulin gene transcription. $J$. Biol. Chem., 280:11887-11894.

Zhou, G., Myers, R., Li, Y., Chen, Y., Shen, X., Fenyk-Melody, J., et al. 2001. Role of AMP-acitvated protein kinase in mechanism of metformin action. J. Clin. Invest., 108(8): 1167-74.

Zimmet, P.Z. 1999. Diabetologia, 42: 499518.

\section{How to cite this article:}

Utsav, Baidyanath Kumar and Atul Kumar. 2016. Diabetes Mellitus and its Control by Ocimum sanctum Extract in Mice Diabetic Model. Int.J.Curr.Microbiol.App.Sci. 5(11): 795-810. doi: http://dx.doi.org/10.20546/ijcmas.2016.511.091 